\title{
Factors Associated with Episiotomy Practices in Bahirdar City, Ethiopia: A Cross-Sectional Study
}

This article was published in the following Dove Press journal:

Risk Management and Healthcare Policy

Fentahun Beyene (D)

Azezu Asres Nigussie

Simachew Kassa Limenih

Azimeraw Arega Tesfu (D)

Kihinetu Gelaye Wudineh

Department of Midwifery, College of Medicine and Health Sciences, Bahir Dar University, Bahir Dar, Ethiopia
Correspondence: Fentahun Beyene Email yenefenta84@gmail.com
Background: Episiotomy is the surgical enlargement of the vaginal orifice during the last part of the second stage of labor or childbirth by an incision to the perineum. The World Health Organization advises the use of episiotomy on a restricted and selective basis. Indeed, the rate of episiotomy in developed countries is decreasing, but in developing countries, including Ethiopia, it still remains high. Therefore, this study tried to assess the proportion and factors associated with episiotomy among women who gave birth at Felege Hiwot Referral Hospital, Bahir Dar City, North West Ethiopia, 2017.

Methods: An institution-based cross-sectional study was conducted among 411 mothers from February to April 2017. Data were collected through face-to-face interviews and supported by observation using standard checklist with systematic random sampling technique. Data was entered by Epi Info and analyzed by SPSS version 23. The association between variables was analyzed using bivariable and multivariable logistic regression model. P-value $<0.05$ at $95 \%$ CI was considered to be statistically significant.

Results: The proportion of episiotomy was $41.1 \%$ with 95\% CI $(36.5 \%, 46.2 \%)$. Multivariable logistic regression showed that primiparity $(\mathrm{AOR}=6.026,95 \% \mathrm{CI}$ $(3.542,10.253))$, prolonged second stage of labor $(\mathrm{AOR}=4.612,95 \%$ CI $(2.247,9.465))$, instrument delivery $(\mathrm{AOR}=3.933,95 \% \mathrm{CI}(1.526,10.141))$, using oxytocin $(\mathrm{AOR}=2.608$, $95 \%$ CI $(1.431,4.751))$, medical resident attendant $(\mathrm{AOR}=3.225,95 \% \mathrm{CI}(1.409,7.382))$ and birth weight $\geq 4000$ grams $(\mathrm{AOR}=5.127,95 \% \mathrm{Cl}(1.106,23.772)$ ) were significantly associated with episiotomy practice.

Conclusion: The proportion of episiotomy was high. Parity, using oxytocin, second-stage labor duration, instrument delivery, birth weight, and delivery attendant were statistically significant factors for episiotomy practice. Therefore, as per our findings, we suggest awareness creation, and the setting and use of new national guidelines, the practice of routine episiotomy should be abandoned, and selective and restrictive use of episiotomy is highly advised.

Keywords: episiotomy, women, Bahir Dar, Ethiopia

\section{Background}

Episiotomy is the surgical enlargement of the vaginal orifice during the last part of the second stage of labor or childbirth by an incision to the perineum. ${ }^{1,2}$ Only two major types of episiotomy (median and mediolateral) are usually described in standard obstetric and midwifery texts. ${ }^{1,3-5}$ Midline episiotomies are common in the USA, where mediolateral episiotomy is most commonly performed, as in Europe. ${ }^{6}$ The procedure was suggested prior to assisted vacuum- or forceps delivery, shoulder dystocia, breech delivery, macrosomic fetuses, and persistent occiput posterior positions in the case of abnormal labor progression, and non-reassuring 
fetal heartrate pattern. ${ }^{7-10}$ It also stated episiotomy as a risk factor of spontaneous perineal tear, subsequent pelvic floor dysfunction, urinary and fecal incontinence, sexual dysfunction, and fetal head injury, medical resident and individual professional judgment was decreased in order to accelerate the second stage of labor. ${ }^{11,12,24,32}$ In the 1920 s a number of reviews were started and then routine episiotomy was advocated. ${ }^{13}$ However, when the first clear clinical studies were released, the long-held assumptions that postoperative pain is less and that recovery improved with an episiotomy compared to a tear seemed to be wrong. ${ }^{10,14}$ Some studies have shown a protective impact on injuries to the obstetric anal sphincter, ${ }^{15}$ although others indicate that assuming that regular episiotomy decreases perineal/ vaginal trauma is not warranted by current evidence, but it has undue adverse effects such as extreme perineal trauma, pelvic floor dysfunction, or prolapse of the pelvic organ compared to restrictive episiotomy usage. ${ }^{10,16,17}$ In addition, episiotomy has been associated with an increased risk of anal postpartum incontinence, dyspareunia, increased discomfort, severe bleeding, wound hematoma, and infection, implying minimal practice. ${ }^{17,18}$ Therefore, indications for routine episiotomy are not well supported, restrictive use of episiotomy is advocated. ${ }^{19,20}$ The Royal College of Obstetricians and Gynecologists (RCOG) sets a conservative episiotomy policy guideline that is: $<30 \%$ in general, $<50 \%$ for primiparous, $<10 \%$ for multiparas. ${ }^{2}$ The lack of evidence on the efficacy of episiotomy in general is also expressed by WHO 2018 and suggests restrictive episiotomy use, although no particular rate is suggested. ${ }^{22}$ The population-based analysis in France reveals that overall, the national episiotomy rate for vaginal deliveries decreased considerably from $26.7 \%$ in 2007 to $19.9 \%$ in $2014 .^{23}$ The total episiotomy incidence decreased from $20.3 \%$ in 2002 to $9.4 \%$ in 2011 in the United States. ${ }^{24}$ In one European study, episiotomy rates ranged from $3.7 \%$ in Denmark to $75 \%$ in Cyprus. ${ }^{25}$ In some African studies, it ranges from $63.3 \%$ (South Africa) to $100 \%$ (Guatemala) for nulliparous women and other evidence in Rwanda has been reported for nulliparous $80.1 \%$ and $19.9 \%$ for multiparous women. ${ }^{26-28}$ The episiotomy performance in Ethiopia specifically, is high. ${ }^{29-33}$ The rate of episiotomy in developed countries is on the decline, but in developing countries it remains high. While episiotomy practice has become a common issue among mothers who have delivered vaginally in Ethiopia, studies are limited to show the extent of the problem. Therefore, this study aimed to assess the proportion and factors associated with, episiotomy among mothers who vaginally delivered in Bahir Dar City Felege Hiwot Referral Hospital, North West Ethiopia.

\section{Methods}

\section{Study Design, Period and Area}

Institutional-based cross-sectional study was conducted from February to April 2017 at Felege Hiwot Referral Hospital, Bahir Dar City, Ethiopia. Bahir Dar City is the capital city of the Amhara National Regional State, located at about $565 \mathrm{~km}$ north west of Addis Ababa (the capital city of Ethiopia). Felege Hiwot Referral Hospital is a tertiary referral hospital. It provides service for an estimated 7 million people from the surrounding area, and has a separate on-site maternity facility which serves around 6000 deliveries per year.

\section{Population}

All women who gave birth vaginally after gestational age of viability ( $\geq 28$ weeks in Ethiopia context) during the study period were included as study population.

\section{Sample Size Determination and Sampling Technique}

Sample size was determined using single population proportion formula with the following assumptions; the proportion of women who had episiotomy was $42 \%,{ }^{38}$ marginal error $5 \%$, value for $95 \%$ CI (1.96), and nonresponse rate of $10 \%$, the the final sample size was 411 .

The study participant was selected by systematic sampling technique every two intervals. The first study participant was selected by lottery method; then the next study participant was identified systematically in every other interval until the required sample size was achieved.

\section{Data Collection Procedure}

A standardized questionnaire containing sociodemographic characteristics, obstetric variables and other variables related to the risk of exposure to the outcome, in English was prepared in accordance with the research objectives and the local situation of the study area. The questionnaire was then translated to Amharic and back to English to ensure the instrument's accuracy. A total of three data collectors (Bachelor of Science in Midwifery) who were working outside the study area and one supervisor (Master of Science in Clinical Midwifery), were recruited. Then one day of training was given on collection 
of data by chart review supported with face-to-face interview and with observation with standard check list to control under-registration of clinical data.

\section{Data Quality Assurance}

After an exhaustive analysis of applicable literature, the data collection method was prepared. The questionnaire pre-test was conducted on $5 \%$ of respondents at a referral hospital with equivalent settings, and changes were made accordingly. Any mistake, uncertainty or incompleteness found was immediately corrected. For one day, data collectors and supervisors were trained on the contents of the questionnaire, the intent of the analysis, the method of collecting data, confidentiality, the right of respondents and informed consent (including how to take informed consent from participants aged less than 18 years). During data collection and also immediately after data collection by the supervisor and principal investigator, the completeness of the data was reviewed by data collectors.

\section{Data Processing, Analysis, and Interpretation}

During the data collection process, supervisor and principal investigator reviewed the data for its completeness and accuracy. The collected data were cleaned, coded and entered using Epi Info version 3.7 and then exported for review to SPSS version 23. To summarize the results, descriptive analysis was performed. Analysis of binary logistic regression was conducted to see the relationship between the independent and outcome variable. In the multivariable logistic regression analysis, all explanatory variables with $\mathrm{p}<0.2$ were entered and relevant associations were established based on $\mathrm{p}<0.05$ and modified odd ratio (AOR) with 95\% CI. Using the Hosmer-Lemeshow goodness of fit test, the final model was mounted. The study's final outcome was presented in the form of texts and tables.

\section{Ethics Approval and Consent to Participate}

Ethical clearance was obtained from the institutional review board of Bahir Dar University. A formal letter request of cooperation was written to Bahir Dar city health office. Written consent was obtained from each study participant and also assent was obtained from their guardian for those aged less than 18 years old. Confidentiality of information and privacy was maintained.

\section{Result}

\section{Socio-Demographic Characteristics}

A total of 411 women who vaginally gave birth were enrolled in the study with $100 \%$ response rate. The majority of participants, (369 (89.8\%)) were in the age group $20-34$ years with a mean age of $26.26 \pm 4.66$ years. The majority of participants, (264 (64.2\%)) were in urban residency. Of the respondents, about 191 (46.5\%) were secondary and above educational levels (Table 1).

\section{Obstetric Characteristics}

From the total (411) of study participants 169 (41.1\%) (CI95\% 36.5-46.2\%) of them had episiotomy. Three fourths $(310(75.4 \%))$ of participants were delivery at term gestational age, and $154(37.5 \%)$ of participants were primiparous. One hundred-seventy $(41.4 \%)$ of them were admitted in latent stage of labor, and for 291 (70.8\%) of the mothers labor was accomplished spontaneously. Ninety-nine $(24.1 \%)$ of them stayed for more than 2 hours during second stage of labor at the delivery coach. Regarding mode of delivery, 357 (86.9\%) of them delivered spontaneously followed by $45(10.9 \%)$ of the mothers by instrument- assisted delivery. The majority $394(95.9 \%)$ of them presented with vertex presentation and $340(82.7 \%)$ of them in occipito anterior position (Table 2).

Table I Socio-Demographic Characteristics of the Participants at Felege Hiwot Referal Hospital, Bahir Dar, Ethiopia, February 2-April 30, 2017 ( $n=41 \mathrm{I})$

\begin{tabular}{|l|l|l|}
\hline Variables & Frequency & Percent \\
\hline Age (years) & & \\
$15-19$ & 12 & 2.9 \\
$20-34$ & 369 & 89.8 \\
$\geq 35$ & 30 & 7.3 \\
\hline Residence & & \\
Urban & 264 & 64.2 \\
Rural & 147 & 35.8 \\
\hline Educational level & & \\
No formal education & 143 & 34.8 \\
Primary level & 77 & 18.7 \\
Secondary level and above & 191 & 46.5 \\
\hline Occupation & & \\
House wife & 239 & 58.2 \\
Government employee & 67 & 16.3 \\
Merchant & 87 & 21.2 \\
Farmer & 18 & 4.4 \\
\hline
\end{tabular}


Table 2 Distribution of Participants by Obstetric Characteristics at Felege Hiwot Referal Hospital, Bahir Dar, Ethiopia, February 2-April 30, $2017(n=4 I I)$

\begin{tabular}{|c|c|c|}
\hline Variables & Frequency & Percent \\
\hline \multicolumn{3}{|l|}{ Gestational age (weeks) } \\
\hline$<37$ & 87 & 21.2 \\
\hline $37-4 \mid+6$ & 310 & 75.4 \\
\hline$\geq 42$ & 14 & 3.4 \\
\hline \multicolumn{3}{|l|}{ Parity } \\
\hline Primipara & 154 & 37.5 \\
\hline Multipara & 257 & 62.5 \\
\hline \multicolumn{3}{|l|}{ Previous history of mode of delivery } \\
\hline Spontaneous vaginal delivery & 156 & 57.2 \\
\hline Episiotomy assisted & 82 & 34.7 \\
\hline By caesarean section & 19 & 8.1 \\
\hline \multicolumn{3}{|l|}{ Ante natal care follow up } \\
\hline Yes & 391 & 95.1 \\
\hline No & 20 & 4.9 \\
\hline \multicolumn{3}{|l|}{ Labor status during admission } \\
\hline Latent stage of labor & 170 & 41.4 \\
\hline Active stage of labor & 159 & 38.7 \\
\hline Second stage of labor & 43 & 10.5 \\
\hline No labor & 39 & 9.5 \\
\hline \multicolumn{3}{|l|}{ Oxytocin used } \\
\hline No & 291 & 70.8 \\
\hline Yes & 120 & 29.2 \\
\hline \multicolumn{3}{|l|}{ Duration of $2 n d$ stage of labor } \\
\hline$\leq \mathrm{lhr}$ & 169 & 41.1 \\
\hline I.I-2hr & 143 & 34.8 \\
\hline$>2 \mathrm{hr}$ & 99 & 24.1 \\
\hline \multicolumn{3}{|l|}{ Number of neonate } \\
\hline Single & 397 & 96.6 \\
\hline Twin & 14 & 3.4 \\
\hline \multicolumn{3}{|l|}{ Presentation } \\
\hline Cephalic & 394 & 95.9 \\
\hline Breech & 17 & 4.1 \\
\hline \multicolumn{3}{|l|}{ Mode of delivery } \\
\hline Spontaneous vaginal delivery & 357 & 86.9 \\
\hline Instrument-assisted delivery & 45 & 10.9 \\
\hline Assisted breech delivery & 9 & 2.2 \\
\hline \multicolumn{3}{|l|}{ Pregnancy condition during labor } \\
\hline Normal gestation & 349 & 84.9 \\
\hline Gestational hypertension & 38 & 9.2 \\
\hline Diabetes & 8 & 1.9 \\
\hline Others* & 16 & 3.9 \\
\hline \multicolumn{3}{|l|}{ Episiotomy } \\
\hline Yes & 169 & 41.1 \\
\hline No & 242 & 58.9 \\
\hline
\end{tabular}

(Continued)
Table 2 (Continued).

\begin{tabular}{|l|l|l|}
\hline Variables & Frequency & Percent \\
\hline Delivery attendant & & \\
Midwives & 236 & 57.4 \\
Medical residents & 96 & 23.4 \\
Intern medical student & 79 & 19.2 \\
\hline Birth weight & & \\
$2500-3999 g m$ & 357 & 86.9 \\
$\leq 2499 g m$ & 33 & 8 \\
$\geq 4000 g m$ & 21 & 5.1 \\
\hline Sex of newborn & & \\
Male & 206 & 50.1 \\
Female & 205 & 49.9 \\
\hline
\end{tabular}

Notes: *HIV ADS, Anemia, Asthma, Goiter and Chorioamnionitis.

\section{Simple and Multivariable Logistic Regression Analysis of Factors Associated with Episiotomy}

Among mothers who had episiotomy 99 (64.3\%) of them were primiparous whereas $70(27.2 \%)$ of them were multiparous. In bivariate analysis variables associated with episiotomy were, residence, education, occupation, gestational age, parity, labor pattern, duration of second stage of labor, mode of delivery, delivery attendant and birth weight. But, after adjusting for possible confounder by multivariable analysis, factors that remained significantly associated with a greater risk of episiotomy were: primiparous $(\mathrm{AOR}=6.03$; $95 \% \quad$ CI $\quad(3.54,10.25) ; \quad \mathrm{P}=<0.001)$, using oxytocin drug $\quad(\mathrm{AOR}=2.61 ; 95 \%$ CI $(1.43,4.75) ; \mathrm{P}=0.002)$, a prolonged second stage of labor $(\mathrm{AOR}=4.61 ; 95 \%$ CI (2.25,9.47); $\mathrm{P}=<0.001)$, delivery attended by medical residents ( $\mathrm{AOR}=3.23 ; 95 \% \mathrm{CI}(1.41,7.38) ; \mathrm{P}=0.006)$, instrument delivery $(\mathrm{AOR}=3.93 ; 95 \% \mathrm{CI}(1.53,10.14) ; \mathrm{P}=0.037)$ and birth weight $\geq 4000 \mathrm{gm}(\mathrm{AOR}=5.13 ; 95 \% \mathrm{CI}(1.11,23.77) ; \mathrm{P}=$ 0.001 ), as statistically significant (Table 3 ).

\section{Discussion}

This study identified that the proportion of episiotomy among laboring mothers who gave birth vaginally was $41.1 \%$ with $95 \%$ CI (36.5-46.2). The proportion episiotomy among nulliparous women was $64.3 \%$ whereas among multiparous $27.2 \%$ women underwent episiotomy at the time of their vaginal delivery. This result is not in line with international guidelines and recommendations, such as those recommended by the Royal College of Obstetricians (RCOG) that recommends $<30 \%$ in general, 
Table 3 Logistic Regression Analysis of Factors Associated with Episiotomy at Felege Hiwot Referal Hospital, Bahir Dar, Ethiopia, February 2-April 30, $2017(n=4 I I)$

\begin{tabular}{|c|c|c|c|c|c|}
\hline \multirow[t]{2}{*}{ Variable } & \multicolumn{2}{|c|}{ Episiotomy } & \multirow[t]{2}{*}{ COR $(95 \% \mathrm{Cl})$} & \multirow[t]{2}{*}{ AOR $(95 \% \mathrm{Cl})$} & \multirow[t]{2}{*}{ p-value } \\
\hline & Yes (\%) & No (\%) & & & \\
\hline \multicolumn{6}{|l|}{ Residence } \\
\hline Urban & $128(48.5)$ & $136(51.5)$ & 1 & I & \\
\hline Rural & $4 I(27.9)$ & $106(72.1)$ & $0.4 I(0.26,0.63)$ & $0.66(0.27,1.60)$ & 0.360 \\
\hline \multicolumn{6}{|l|}{ Educational level } \\
\hline No formal education & $30(21)$ & $113(79)$ & $0.24(0.15,0.40)$ & $0.56(0.28,1.15)$ & 0.117 \\
\hline Primary level & $40(52)$ & $37(48)$ & $1.00(0.59,1.70)$ & $\mathrm{I} .87(0.83,4.2 \mathrm{I})$ & 0.126 \\
\hline Secondary level and above & $99(51.8)$ & $92(48.2)$ & 1 & 1 & \\
\hline \multicolumn{6}{|l|}{ Occupation } \\
\hline Government employee & $43(69.4)$ & $24(30.6)$ & 1 & 1 & \\
\hline House wife & $85(35.6)$ & $154(64.4)$ & $0.30(0.17,0.54)$ & $0.79(0.29,2.16)$ & 0.653 \\
\hline Merchant & $30(34.5)$ & $57(65.5)$ & $0.29(0.15,0.57)$ & $0.45(0.17,1.19)$ & 0.110 \\
\hline Farmer & $\mathrm{II}(6 \mathrm{I} . \mathrm{I})$ & $7(38.9)$ & $0.87(0.30,2.56)$ & $0.27(0.05, I .42)$ & 0.125 \\
\hline \multicolumn{6}{|l|}{ Gestational age (weeks) } \\
\hline$<37$ & $18(20.7)$ & $69(79.3)$ & $\mathrm{I}$ & I & \\
\hline$\geq 37$ & $|5|(46.6)$ & $173(53.4)$ & $0.29(1.90,5.87)$ & $\mathrm{I} .2 \mathrm{I}(0.548,2.8 \mathrm{I})$ & 0.604 \\
\hline \multicolumn{6}{|l|}{ Parity } \\
\hline Primipara & $99(64.3)$ & $55(35.7)$ & $4.80(3.13,7.38)$ & $6.02(3.54,10.25)$ & $<0.001$ \\
\hline Multipara & $70(27.2)$ & $187(72.8)$ & 1 & 1 & \\
\hline \multicolumn{6}{|l|}{ Labor } \\
\hline Spontaneous & $87(29.9)$ & $204(70.1)$ & 1 & I & \\
\hline Oxytocin used & $82(68.3)$ & $383(31.7)$ & $5.06(3.19,8.00)$ & $2.60(1.43,4.75)$ & 0.002 \\
\hline \multicolumn{6}{|l|}{ Duration of $2 n d$ stage of labor } \\
\hline$\leq \mathrm{Ihr}$ & $43(25.4)$ & $126(74.6)$ & 1 & 1 & \\
\hline $\mathrm{I} . \mathrm{I}-2 \mathrm{hr}$ & $53(37.1)$ & $90(62.9)$ & $1.72(1.06,2.80)$ & $1.647(0.92,2.94)$ & 0.091 \\
\hline$>2 \mathrm{hr}$ & $73(73.7)$ & $26(26.3)$ & $8.22(4.67,14.48)$ & $4.6 I(2.24,9.46)$ & $<0.001$ \\
\hline \multicolumn{6}{|l|}{ Mode of delivery } \\
\hline Spontaneous delivery & $|3|(36.7)$ & $226(63.3)$ & 1 & I & \\
\hline Instrument-assisted delivery & $35(77.8)$ & $10(22.2)$ & $6.03(2.89,12.59)$ & $3.93(1.52,10.14)$ & 0.005 \\
\hline Assisted breech delivery & $3(33.3)$ & $6(66.7)$ & $0.86(0.21,3.50)$ & $2.12(0.40,11.19)$ & 0.373 \\
\hline \multicolumn{6}{|l|}{ Delivery attendant } \\
\hline Midwife & $78(33.1)$ & $158(66.9)$ & $1.06(0.61,1.84)$ & $1.22(0.62,2.40)$ & 0.563 \\
\hline Resident & $66(68.8)$ & $30(31.2)$ & $4.75(2.50,9.02)$ & $3.22(1.40,7.38)$ & 0.006 \\
\hline Intern medical student & $25(31.6)$ & $54(68.4)$ & 1 & 1 & \\
\hline \multicolumn{6}{|l|}{ Birth weight (grams) } \\
\hline$\leq 2499$ & $6(18.2)$ & $27(81.8)$ & I & 1 & \\
\hline 2500-3999 & $152(42.6)$ & $205(57.4)$ & $3.33(1.34,8.28)$ & $2.5(0.81,7.77)$ & 0.110 \\
\hline$\geq 4000$ & II(52.4) & $10(47.6)$ & $4.95(1.44,16.95)$ & $5.12(1.10,23.77)$ & 0.037 \\
\hline
\end{tabular}

Notes: AOR and P-values written in bold font show staticstically significant variables.

$<50 \%$ for primiparous, and $<10 \%$ for multiparas; ${ }^{21}$ or American College of Obstetrics and Gynecology $(\mathrm{ACOG} 2016)^{19}$ and WHO recommendations which suggestrestrictive use of episiotomy, although no specific rate is recommended. ${ }^{22}$ It was higher than previous studies done in Brazil $(29.1 \%)^{34}$ and Vietnam $\left.(29.9 \%)\right)^{35}$ This disparity may be due to the difference in the design of the study and the time gap; as the previous studies were retrospective cross-sectional studes, some underregistration may result and could lead to a lower level of 
episiotomy procedure. In addition to this, the number of trained health professionals available with technology development and the use of a standard guideline related to episiotomy indications and a deliberate effort to minimize the use of episiotomy in the study center may vary in that setup. On the contrary, it was lower than a study done in Latin America (50\%). ${ }^{36}$ This discrepancy may be due to the difference in the research duration; in Latin America, the data collection period was almost a year and that may demonstrate the actual prevalence of episiotomy by monitoring the seasonal variation of patient flow or the various institutional rules and individual clinical practice may be the different. In addition, the discrepancies may be explained by inappropriate reporting, meaning that the tear may be reported as an episiotomy by the health provider after fixing it, which may also be attributable to the time gap in the understanding of health professionals regarding regular episiotomy use. Whereas the finding is in line with the study done in Burikinafaso $(37 \%)^{37}$ and in Nigeria (45\%). ${ }^{11}$ The possible explanation for this consistency might be similar distribution of qualified personnel in adherence to the recommendation of selective use of episiotomy.

When comparing this result with Ethiopia studies, it coincides with study found in Tikur Anbessa Hospital Addis Ababa (40.2\%) ${ }^{37}$ and in Markos (42\%). ${ }^{38}$ The possible explanation of consistency might be due to similar patient flow and similar practice level, serving as referral and teaching hospital level. However; it is slightly higher than the result in Shire town (35\%), ${ }^{29}$ and Mizan Aman $30.6 \%{ }^{30}$ which might be due to the site being a training hospital where trainee doctors would tend to perform more episiotomies to practice, or variations in data registrations quality. And also it is higher than study done in Jima $(25 \%)^{31}$ which might be because data collection was not only by document review but also supported with interview which prevents under-registration of clinical data. Moreover, this might be because of the new strategy of the ministry of health of Ethiopia, increasing distribution of ambulances and the increased awareness creation ability of health extension workers in rural areas which decreases the number of women who deliver at home by bringin them to the hospitals.

The analysis of this study showed that primiparous women had a 6-fold greater likelihood of having episiotomy compared to multiparous women. This is in agreement with findings reported in some parts of the world; Latin America, ${ }^{36}$ Brazil, $^{32}$ Vietnam, ${ }^{35}$ Saudi Arabia, ${ }^{26}$
$\operatorname{Iran}^{33}$ and some parts of Ethiopia; Addis Ababa Tikur Anbessa Hospital, ${ }^{37}$ Jima Teaching Hospital, ${ }^{31}$ Mizan Aman General Hospital, ${ }^{30}$ Debre-Markos Referral Hospital, ${ }^{38}$ and Shire Town. ${ }^{29}$ The potential explanation may be that the perineum of primiparous parturient provides a tenser musculature than multiparous women, which may lead to increased release duration of cephalic pole, causing episiotomy to be performed by the delivery attendant. Other explanations may be attributable to the fact that care providers are helpful for first births to protect the perineum, taking into account the old guidelines of regular episiotomy results. In addition, the difference may be due to the case load and care providers may not have patience to remain with primiparous mothers for a longer time, because they have a comparatively longer labour period than multiparous mothers. Episiotomy performance in the first birth is a risk factor for the occurrence of spontaneous lacerations in subsequent births. Nevertheless, these data may reflect a more liberal practice of episiotomy in primiparous rather than any real need for the procedure in this group of women.

The statistical analysis of this study implies that: start of labor assisted by oxytocin were 5 times more likely to perform episiotomy than labor allowed to evolve normally. Our results concur with findings in Latin America, ${ }^{36}$ Brazil, ${ }^{32}$ Vietnam, ${ }^{35}$ Iran, ${ }^{33}$ and in Shire town Ethiopia. ${ }^{29}$

The potential reason may be if labor does not start and progress naturally that does not bring perineal muscle physiological relaxation and then could increase labor period, it could also be due to intentional use in an effort to reduce labor time and could imply a more interventionist approach by the delivery attending professional. Induced deliveries can also be more dystocic and can cause a cascade of other interventions that may result in fetal heart rate patterns of non-reassurance that require an episiotomy to be performed by the caregiver.

The statistical analysis of the relationship between episiotomy and instrument-assisted deliveries shows that the use of instruments, especially forceps, has involved 3.9-fold probability of performing episiotomy. This statistic coincides with the findings in Latin America, ${ }^{36}$ Brazil, ${ }^{32}$ Iran, ${ }^{33}$ Saudi Arabia ${ }^{34}$ and some parts of Ethiopia; Addis Ababa Tikur Anbessa Hospital, ${ }^{37}$ Jima Teaching Hospital $^{31}$ and Debre-Markos Referral Hospital. ${ }^{38}$ This relationship may arise from the referral of complex laboring mothers flow to the center for advancing care with greater technological and human resources. Professionals may therefore assume that instrumental 
delivery is an indication of episiotomy to reduce perineal tears, especially when using forceps. However, there is no clear indication for episiotomy when an instrumental delivery is performed; it is believed to result in an increase in severe lacerations of the perineum, with possible damage to anal function. But the role of routine episiotomy in instrumented birth is not well studied and requires more research ${ }^{18}$ Some authors have suggested that episiotomy may not be absolutely necessary in childbirth. ${ }^{39}$

In this study prolonged second stage of labor over 2 hours was 4.6 times higher risk of episiotomy. This finding was also supported by studies; in $\operatorname{Iran}^{33}$ and in Ethiopia; Addis Ababa Tikur Anbessa Hospital 37 and DebreMarkos Referral Hospital. ${ }^{38}$ The potential explanation might be due to the incidence of maternal fatigue that may be as a result of mothers being asked to push down from the early second stage for a long period of time or there could be insufficient provision of any labor support contributing to mothers not pushing after more than 2 hours of efforts and thus prolonging the second stage of labor. So, obstetric care providers were also designed to perform an episiotomy to minimize trauma, fetal distress, and perinatal asphyxia reduction.

The statistical analysis of this result showed that deliveries attended by medical residents were 3 times more likely to have episiotomy than those attended by midwives. This individual professional judgment risk was supported by studies done in Spain $^{24}$ and Brazil. ${ }^{32}$ This may mean that the practice in this center is that residents were often invited only to attend when an established risk factor warranted their attention, or that most of the complex deliveries in this center were performed by senior health professionals in which episiotomy is highly required.

This result reveals that fetal weight $\geq 4000$ gm was 5 times more likely risk of episiotomy which coincides with the findings reported from other centers; in $\mathrm{Spain}^{24}$ and some parts of Ethiopia; in Mizan Aman General Hospital ${ }^{30}$ and in Debre Markos Referral Hospital. ${ }^{38}$ This might be due to fear of perineal laceration, to boost adequate space for higher fetal weight and might be associated with instrument-assisted birth.

\section{Limitation of the Study}

The limitations of this study includethe cross-sectional nature of the study, it is not able to assess some variables related to post-operative outcome.
Since the data collector is a health professional, there might be social desirability bias.

\section{Conclusion and Recommendations}

In this study the proportion of episiotomy was high. Primiparity, prolonged duration of second stage of labor, using oxytocin drug, instrument-assisted delivery, delivery attended by medical residents and birth weight $\geq 4000$ grams were significantly associated with episiotomy practice. As per our findings we suggest emphasis on the restrictive use of episiotomy and with clear indication to reduce its rates and unnecessary procedures. And deal with national policy makers in both governmental and nongovernmental sectors .

\section{Abbreviations}

ANC, ante natal care; APGAR, Appearance, Pulse, Grimace, Activity, Respiration; WHO, World Health Organization.

\section{Data Sharing Statement}

The datasets used and/or analyzed during the current study are available from the corresponding author upon request.

\section{Acknowledgment}

We would like to acknowledge Bahir Dar University, College of Medicine and Health Sciences, Ethiopia for granting us the permission to conduct this research. We are also obliged to thank data collectors, study participants and supervisors for their commitment to take part in the study.

We also thank EPHA for the selection of the paper as poster presentation in the 29 EPHA Annual Conferences and posted online for readers. The abstract of this paper was presented at the 29th EPHA Annual Conference as a poster presentation. The abstract of this paper was realized/posted online and available at: http://www.etpha.org/ conference/index.php/29thConference/29thConference/ paper/view/1042

\section{Author Contributions}

All authors made substantial contributions to conception, study design, execution, and acquisition of data, analysis and interpretation; drafting, revising or critically reviewing the article; journal selection for publication, gave final approval of the version to be published; and agree to be accountable for all aspects of the work. 


\section{Funding}

Bahir Dar University, the funder organization covered the costs of data collectors and supervisors per-diem. Otherwise they had no role in designing the study, manuscript preparation or for publication cost.

\section{Disclosure}

The authors declare that they have no competing interests.

\section{References}

1. Carroli G, Mignini L. Episiotomy for vaginal birth. Cochrane Database Syst Rev. 2009.

2. Thacker SB, Banta DH. Benefits and risks of episiotomy: an interpretative review of the English language literature, 1860-1980. Obstet Gynecol Surv. 1983;38(6):322-338. doi:10.1097/00006254198306000-00003

3. Cunningham FG, McDonald PC, Gant NF, Leveno KJ, Gilstrap LC III. Williams Obstetrics. 21st ed. New York: McGraw-Hill Companies Inc; 2001.

4. Arulkumaran S. Malpresentation, malposition, cephalopelvic dysproportion and obstetric procedures. In: Edmonds DK, editor. Dewhurst's Textbook of Obstetrics and Gynaecology. 7th ed. Oxford: Blackwell Publishing; 2007:213-226.

5. Cohen WR, Romeo R. Childbirth and the pelvic floor. In: Kurjak A, Chervenak FA, editors. Textbook of Perinatal Medicine. 2nd ed. London: Informa Healthcare; 2006:1984-1985.

6. Räisänen S, Vehviläinen-Julkunen K, Heinonen S. Need for and consequences of episiotomy in vaginal birth: a critical approach. Midwifery. 2010;26(3):348-356. doi:10.1016/j.midw.2008.07.007

7. Robinson JN, Norwitz ER, Cohen AP, Lieberman E. Predictors of episiotomy use at first spontaneous vaginal delivery. Obstet Gynecol. 2000;96:214-218.

8. Adaji SE, Shittu SO, Sule ST. Operative vaginal deliveries in Zaria, Nigeria. Ann Afr Med. 2009;8(2):95-99. doi:10.4103/1596-3519.56236

9. Hartmann K, Viswanathan M, Palmieri R, et al. Outcomes of routine episiotomy: a systematic review. JAMA. 2005;293(17):2141-2148. doi:10.1001/jama.293.17.2141

10. Rocker G. Changed pattern in the use of episiotomy in Sewdne. BMJ. 1999;106:95-101.

11. Inyang-Etoh EC, Umoiyoho AJ. The practice of episiotomy in a university teaching hospital in Nigeria: how satisfactory? Int J Med Biomed Res. 2012;1(1):68-72. doi:10.14194/ijmbr.1111

12. Ahmed HM. Midwives' clinical reasons for performing episiotomies in the kurdistan region are they evidence-based? Sultan Qaboos Univ Med J. 2014;14(3):369-374.

13. Homer H, Homer C. Perineal trauma and postpartum perineal morbidity in Asian \& Non- Asian primiparious women giving birth in Australia. JOGNM. 2008;37(4):455-463. doi:10.1111/j.1552-6909.20 08.00259.x

14. Cunningham FG, Leveno KJ, Bloom SL, Hauth JC, Rouse DJ, Spong C. Williams Obstetrics. 21st ed. Mc Graw-Hill Medical Publication Division; 2001:325-326.

15. Gurol-Urganci I, Cromwell DA, Edozien LC. Third- and fourth-degree perineal tears among primiparous women in England between 2000 and 2012: time trends and risk factors. BJOG. 2013;120(12):1516-1525. doi:10.1111/1471-0528.12363
16. Aasheim V. Perineal techniques during the second stage of labour for reducing perineal trauma (review). Cochrane Collab. 2011;(12).

17. Lurie S, Kedar D, Boaz M, Golan A, Sadan O. Need for episiotomy in a subsequent delivery following previous delivery with episiotomy. Arch Gynecol Obstet. 2013;287(2):201-204. doi:10.1007/s00404012-2551-8

18. Chia CC, Huang S-C. Third- and fourth-degree perineal laceration in vaginal delivery. Taiwan J Obstet Gynecol. 2012;51(1):148-152. doi:10.1016/j.tjog.2012.01.035

19. Bulletin AP. Summary; prevention and management of obstetric lacerations at vaginal delivery no.165. Obstet Gynecol. 2016;1 $28:: 411$.

20. Jiang H, Carroli G, Garner P, Garner P. Selective versus routine use of episiotomy for vaginal birth. Cochrane Database Syst Rev. 2017; (2). doi:10.1002/14651858.CD000081.pub3.

21. RCOG. The management of third and fourth degree perineal tears. Green Top Guideline. 2015;29(2).

22. Organization WH. Intrapartum Care for a Positive Childbirth Experience. Geneva: WHO; 2018:150.

23. Karine Goueslard JC, Roussot A, Roussot A, Clesse C, Sagot P, Quantin C. How did episiotomy rates change from 2007 to 2014? Population-based study in France. BMC Pregnancy Childbirth. 2018;18(1):208. doi:10.1186/s12884-018-1747-8

24. Kozhimannil KB, Karaca-Mandic P, Blauer-Peterson CJ, Shah NT, Snowden JM. Uptake and utilization of practice guidelines in hospitals in the united states: the case of routine episiotomy. $J t$ Comm J Qual Patient Saf. 2017;43(1):41-48. doi:10.1016/j. jcjq.2016.10.002

25. Blondel B, Alexander S, Bjarnadóttir RI. Variations in rates of severe perineal tears and episiotomies in 20 European countries: a study based on routine national data in Euro-Peristat project. Acta Obstet Gynecol Scand. 2016;95(7):746-754. doi:10.1111/aogs.12894

26. Dotun Ogunyemi JM, Mohsen B. Demographic variation and clinical association of episiotomy and sever perineal laceration in vaginal delivery. JNMA. 2006;98(11):1874.

27. Mbukani R, Kakoma JB. Is nulliparity a risk factor for poor obstetrical and neonatal outcomes in rwandan district hospitals ? A prospective observational study at muhima district hospital. Rwanda Med J. 2012;69(1):50-53.

28. Hernández P. Factors affecting the performance of a selective episiotomy in nulliparous women. Julio. 2014;35:412-424.

29. Kidane Niguse GG, Gebrehiwot H. Episiotomy Practice and its associated factors among mothers who gave birth vaginally at public health institutions of Shire Town, Northern Ethiopia. Res Rev $J$ Health Prof. 2016;6(1).

30. Kumera M, Ademe B, Akessa G. Assessment of episiotomy practice in Mizan Aman General Hospital, Ethiopia. J Health Med Nurs. 2015;20:2422-8419.

31. Marai W. Atwo years retrospective review of episiotomy at Jimma Teaching Hospital, southern Western Ethopia. Ethiop Med J. 2002;40 (2):141-148.

32. Giordana Campos B, Clementino STP, Luz PFND, et al. Risk factors for episiotomy: a case-control study. Rev Assoc Med Bras. 2014;60 (5):465-472. doi:10.1590/1806-9282.60.05.015

33. Rasouli M, Keramat A, Khosravi A, Mohabatpour Z. Prevalence and factors associated with episiotomy in Shahroud City, Northeast of Iran. Int $J$ Womens Health Reprod Sci. 2016;4(3):125-129. doi:10.15296/ijwhr.2016.29

34. Cynthia M. Prevalence and factors associated with practice of episiotomy at a maternity schoolin RECIFE, Brazil. Rev Assoc Med Bras. 2010;56(3):333-339. 
35. Anh T, Khambalia A, Ampt A, et al. Episiotomy rate in Vietnamese-born women in Australia: support for a change in obstetric practice in Viet Nam. Bull World Health Organ. 2013;91 (5):350-356. doi:10.2471/BLT.12.114314

36. Meseguer C. Episiotomy and its relationship to various clinical variables that influence its performance. Rev Lat Am Enfermagem. 2016;24:e2793.
37. Lakew Z, Kiros K. Magnitude of episiotomy in a teaching hospital in Addis Ababa, Ethiopia. Ethiop Med J. 2006;44(3):205-209.

38. Aynalem FW. Magnitude and factors associated with episiotomy: World Congress on midwifery and women's health. $J$ Womens Health Care. 2016.

39. Amorim M, Katz L. The role of episiotomy in modern obstetrics. Femina. 2008;36:47-54.

\section{Publish your work in this journal}

Risk Management and Healthcare Policy is an international, peerreviewed, open access journal focusing on all aspects of public health, policy, and preventative measures to promote good health and improve morbidity and mortality in the population. The journa welcomes submitted papers covering original research, basic science, clinical \& epidemiological studies, reviews and evaluations, guidelines, expert opinion and commentary, case reports and extended reports. The manuscript management system is completely online and includes a very quick and fair peer-review system, which is all easy to use. Visit http://www.dovepress.com/testimonials.php to read real quotes from published authors.

Submit your manuscript here: https://www.dovepress.com/risk-management-and-healthcare-policy-journal 